KAPL-P-000178

(K97065)

CONF-9705/19--

\title{
MINORITY-CARRIER TRANSPORT InGaAsSb THERMOPHOTOVOLTAIC DIODES
}

G. Charache, R. U. Martinelli, et. al.

May 1997

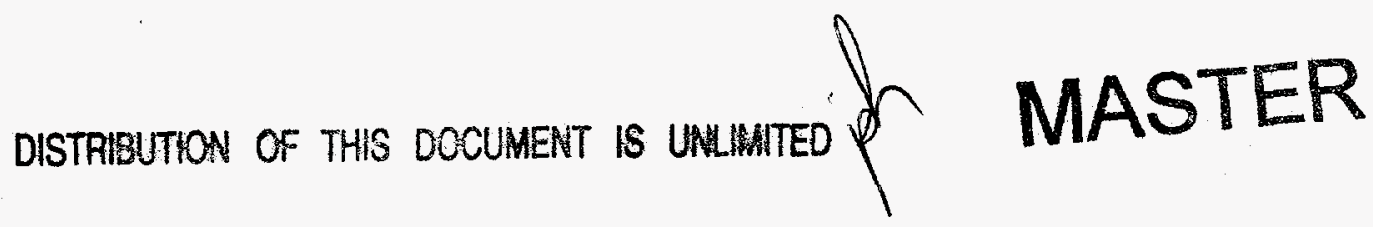

\section{NOTICE}

This report was prepared as an account of work sponsored by the United States Government. Neither the United States, nor the United States Department of Energy, nor any of their employees, nor any of their contractors, subcontractors, or their employees, makes any warranty, express or implied, or assumes any legal liability or responsibility for the accuracy, completeness or usefulness of any information, apparatus, product or process disclosed, or represents that its use would not infringe privately owned rights. 


\section{DISCLAIMER}

This report was prepared as an account of work sponsored by an agency of the United States Government. Neither the United States Government nor any agency thereof, nor any of their employees, makes any warranty, express or implied, or ascumes any legal liability or responsibility for the accuracy, completenese, or usefulness of any information, apparatus, product, or process disclosed, or represents that its use would not infringe privately owned rights. Referesce berein to any specilic commercial product, process, or service by trade name, tradernaric, inanufacturet, or otherwise does not necessarily constitute or imply its endorsement, recommendation. or favoring by the United States Goverameat or any agency thereof. The views and opinions of authors expressed berein do not necsesarily state or reflect those of the United States Governmeat or any agency thereof. 


\section{DISCLAIMER}

Portions of this document may be illegible in electronic image products. Images are produced from the best available original document. 


\title{
Minority-Carrier Transport in InGaAsSb Thermophotovoltaic Diodes
}

\author{
R. U. Martinelli, D. Z. Garbuzov, H. Lee, N. Morris, T. Odubanjo, \\ and J. C. Connolly \\ Sarnoff Corporation, Princeton, NJ 08543-5300
}

\begin{abstract}
Uncoated InGaAsSb/GaSb thermophotovoltaic (TPV) diodes with $0.56 \mathrm{eV}(2.2$ $\mu \mathrm{m})$ bandgaps exhibit external quantum efficiencies of $59 \%$ at $2 \mu \mathrm{m}$. The devices have electron diffusion lengths as long as $29 \mu \mathrm{m}$ in 8- $\mu \mathrm{m}$-wide $\mathrm{p}$ InGaAsSb layers and hole diffusion lengths of $3 \mu \mathrm{m}$ in $6-\mu \mathrm{m}$-wide $\mathrm{n}$ InGaAsSb layers. The electron and hole diffusion lengths appear to increase with increasing p- and n-layer widths. At $632.8 \mathrm{~nm}$ the internal quantum efficiencies of diodes with 1- to $8-\mu \mathrm{m}$-wide p-layers are above $89 \%$ and are independent of the p-layer width, indicating long electron diffusion lengths. InGaAsSb has, therefore, excellent minority carrier transport properties that are well-suited to efficient TPV diode operation. The structures were grown by molecular-beam epitaxy.
\end{abstract}

\section{Introduction}

There has been a recent interest in thermophotovoltaic (TPV) electric power generation from blackbody sources at about $1000^{\circ} \mathrm{C}[1,2]$. Candidate III-V compound materials for the TPV diode active region are InGaAs grown on InP and InGaAsSb grown on GaSb. Since the bandgap of the optimal TPV diode is about $0.55 \mathrm{eV}$, the InGaAs diodes have a compositionally graded layer interposed between the InP substrate and the InGaAs layer to accommodate the lattice mismatch. The InGaAsSb diodes are lattice-matched to the substrate. Lattice-matched devices may offer more possibilities in terms of bandgap engineering and the variety of material choices, but these advantages are not all clear at present. Nonetheless, while InGaAs diodes currently offer superior performance in terms of quantum efficiency and saturation current, owing in part to their longer-term development [3], InGaAsSb is demonstrating excellent minority-carrier transport characteristics that make it a very attractive material for TPV diodes.

In this paper we show quantum efficiencies of $59 \%$ at $2 \mu \mathrm{m}$ wavelength from an InGaAsSb/GaSb diode. The inferred electron diffusion length in this 
device is $29 \mu \mathrm{m}$. Our spectral quantum efficiency (SQE) curves compare favorably with recently reported results for both InGaAsSb and InGaAs TPV diodes [3].

\section{Experimental Results}

The TPV diodes discussed in this paper are designed to generate electrical power from $1000^{\circ} \mathrm{C}$ blackbody radiation. The active region is a nominally $0.55 \mathrm{eV}$ InGaAsSb $\mathrm{p} / \mathrm{n}$ homojunction. To optimize the power-conversion efficiency, radiation up to the bandgap cut-off wavelength must be maximally absorbed, and the photo-generated carriers must be transported to the $p / n$ junction with minimal loss. This places a tradeoff between widening the active region to increase optical absorption at near-bandgap wavelengths, where the absorption constant is relatively small, and decreasing the $\mathrm{p}$ - and $\mathrm{n}$ layer thicknesses to maximize carrier collection at the junction. The values of the electron and hole diffusion lengths, $L_{e}$ and $L_{h r}$ are critical to the optimization of the TPV structure. In general, long diffusion lengths allow wide active regions, which lead to high quantum efficiencies. We undertook the study of the TPV diode SQE to determine the values of $L_{e}$ and $L_{h}$.

The TPV structures were grown by solid-source, molecular-beam epitaxy (MBE) and were lattice-matched to the GaSb substrates in a manner very similar to that used for the growth of antimonide-based lasers $[4,5]$. To study the transport properties of the diodes, $500-\mu \mathrm{m}$-diameter mesas were etched into the wafers, and individual mesa diodes were evaluated. Figure 1 schematically shows the vertical structure of the TPV diode. 


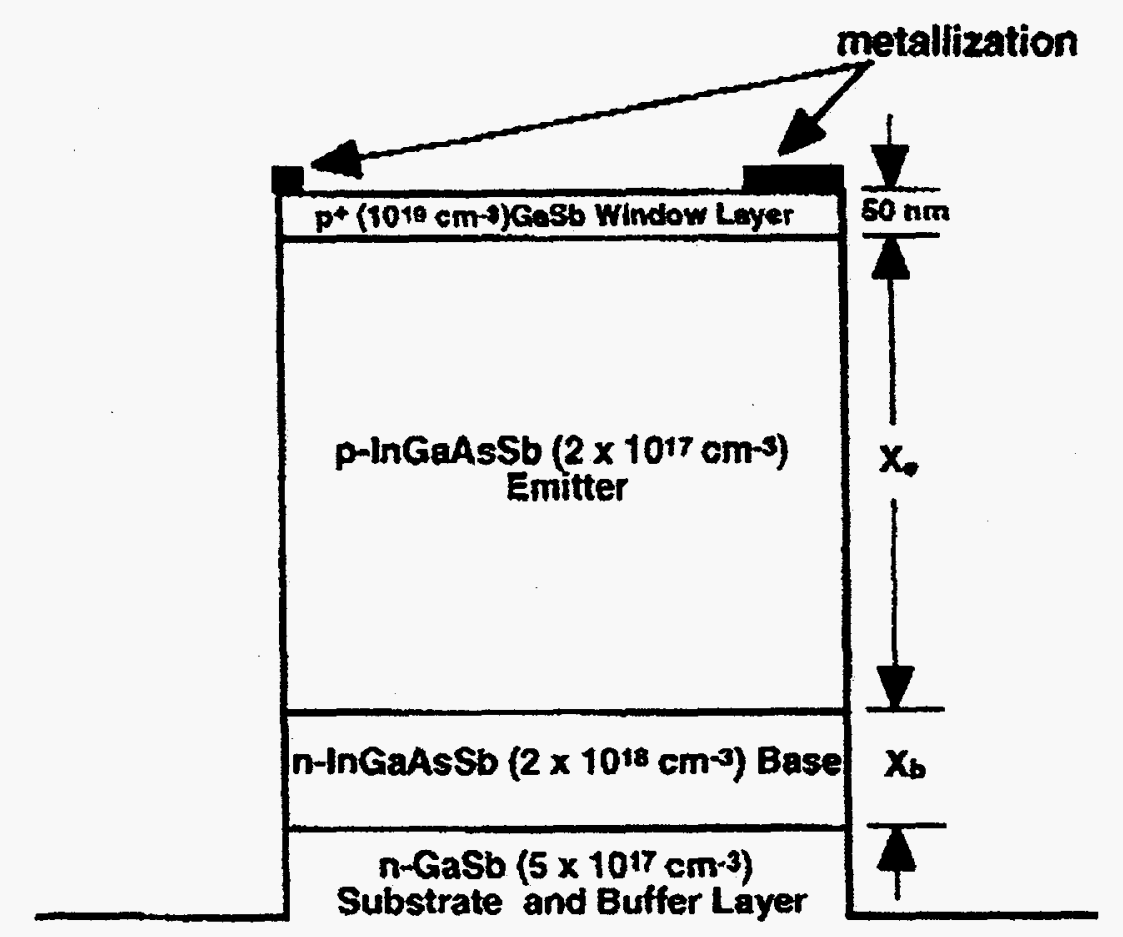

Figure 1. Vertical Layer structure of a p-on-n InGaAsSb TPV diode.

After growing a 500-nm-thick $n-G a S b$ buffer layer on the $n-G a S b$ substrate, the so-called base region is grown $x_{b} \mu \mathrm{m}$ thick. For most of the devices used in this work, $x_{b}$ is 1 to $6 \mu \mathrm{m}$. The n-type base layers are Te-doped to about $2 \times 10^{18}$ $\mathrm{cm}^{-3}$. On top of the base the p-type emitter, Be-doped to $2 \times 10^{17} \mathrm{~cm}^{-3}$, is grown to thicknesses, $x_{c}$ ranging from 1 to $8 \mu \mathrm{m}$. A 50-nm-thick $\mathrm{p}^{+}$GaSb window layer, Be-doped to $10^{19} \mathrm{~cm}^{-3}$, is grown on the emitter, completing MBE growth of this so-called $\mathrm{p}$-on- $\mathrm{n}$ diode. The $\mathrm{GaSb}$ window layer insures very low electron recombination at the $\mathrm{p}^{+}-\mathrm{GaSb} / \mathrm{p}$-InGaAsSb window-layer/emitter interface. While we have grown and characterized n-on-p TPV diodes, this work describes results from p-on-n devices.

Following growth, the wafer is thinned to $150 \mu \mathrm{m}$ and metallized with standard $\mathrm{Au} / \mathrm{Ge} / \mathrm{Ni} / \mathrm{Au}$. The epitaxial surface is patterned and metallized with $\mathrm{Cr} / \mathrm{Au}$, and the mesas are etched several microns into the substrate using a bromine/methanol solution.

Relative SQE curves in the wavelength interval of 1 to $2.5 \mu \mathrm{m}$ were obtained using a monochrometer with a known relative output-power spectrum. The diode's absolute quantum efficiency was measured using a $1.575 \mu \mathrm{m}$ fibered diode laser with a known output-power-versus-laser-current characteristic. The relative SQE data were then adjusted to agree with the $1.575 \mu \mathrm{m}$ absolute 
data. Absolute quantum efficiency measurements were also made at 632.8 nm using a HeNe laser.

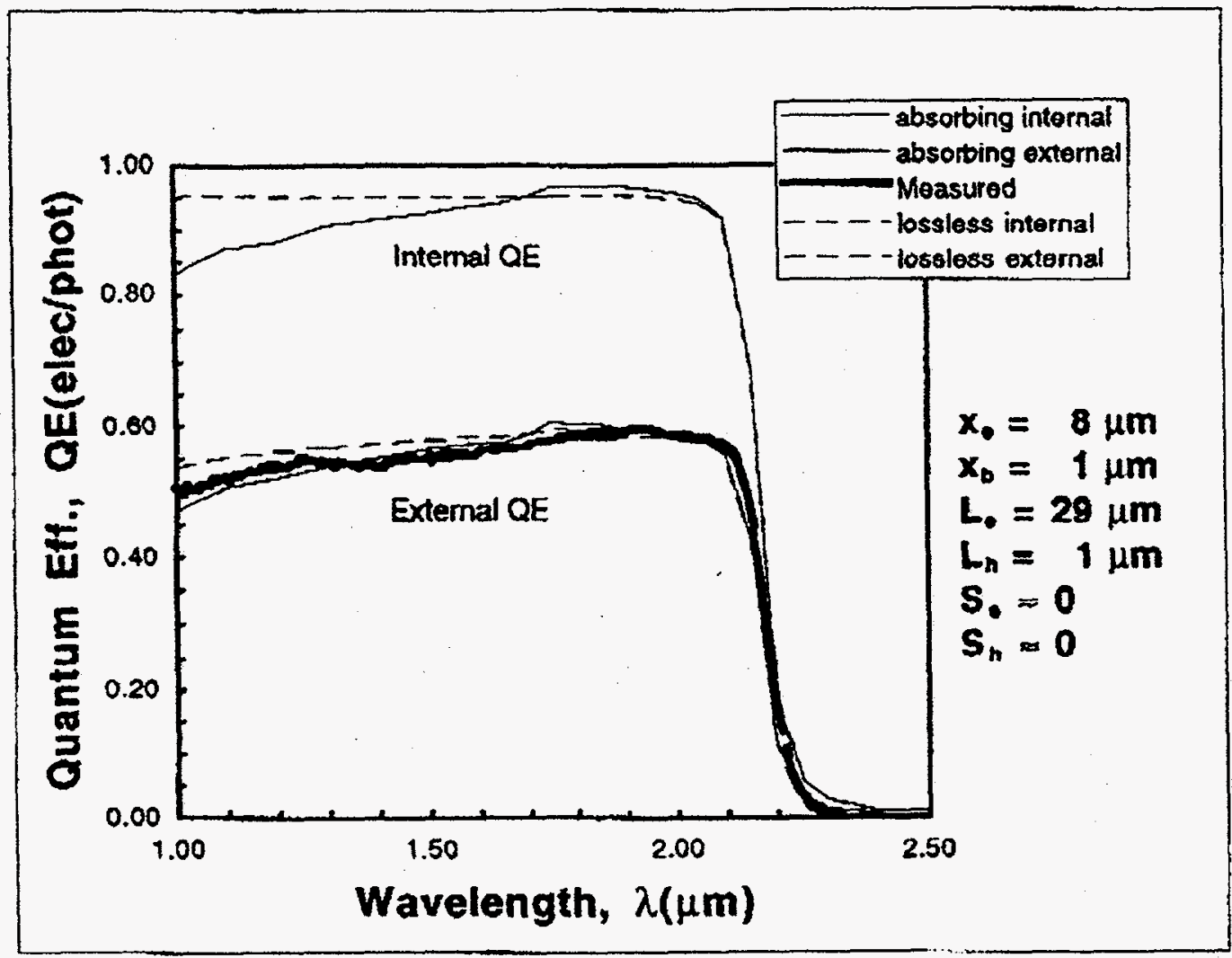

Figure 2. The spectral quantum efficiency of a p-on-n TPV diode having an 8$\mu \mathrm{m}$ emitter and a 1-um base. Model curves show external and internal SQE for absorbing and lossless GaSb window layers.

Figure 2 shows the SQE of a TPV diode having an 8- $\mu \mathrm{m}$ emitter and a $1-\mu \mathrm{m}$ base, along with model curves for external and internal SQE. The measured SQE rises sharply at wavelengths shorter than the bandgap wavelength of 2.2 $\mu \mathrm{m}(0.56 \mathrm{eV})$, reaching a maximum QE of $59 \%$ at $2 \mu \mathrm{m}$. As the wavelength decreases, the SQE slowly decreases to $50 \%$ at $1 \mu \mathrm{m}$.

The model used to fit the SQE data is a simple, one-dimensional minoritycarrier diffusion model commonly employed in SQE data analysis [6]. The measured reflectivity was used to calculate the photon density within the diode. In some cases we used the measured absorption constant of InGaAsSb, but mostly we used semi-empirical absorption data computed through a method similar to that of Borrego [7]. Accounting for absorption by the 50nm-thick GaSb window layer, two sets of SQE curves were calculated: one set assuming that the window layer contributes all electrons photo-generated within it to the emitter (labeled "lossless internal (or external)" in Fig. 2), and 
the other set assuming that the window layer contributes no photo-generated electrons to the emitter (labeled "absorbing internal (or external)" in Fig. 2).

Electron and hole diffusion lengths, $L_{e}$ and $L_{k}$ characterize minority-carrier transport. The base/substrate and the window-layer/emitter interfaces are characterized by recombination velocities $S_{b}$ and $S_{c}$ respectively. Note that we normalize these recombination velocities to the "bulk" recombination velocity $D / L$, where $D$ is the appropriate diffusion constant. In this way $S_{b} \gg$ 1 describes an interface that acts like a sink for holes, and $S_{b} \ll 1$, describes a nearly perfect reflecting interface. The total photo-current comprises contributions from the emitter, base, depletion-region, and possibly from the window layer.

The model curve of external SQE with an absorbing window describes the measured SQE curve in Fig. 2 reasonably well using the following parameters: $L_{e}=29 \mu \mathrm{m}, S_{c}=0, L_{h}=1 \mu \mathrm{m}$, and $S_{b}=0$. Note that in diodes where $x_{e}>x_{b}$, as in this device, the influence of the base on the SQE is negligibly small, and the parameters describing hole transport are, therefore, inaccurate. The values we used in this case were obtained from diodes having 1- $\mu \mathrm{m}$ bases and emitters. The best fit to the external SQE for a lossless window layer gives $L_{e}=25 \mu \mathrm{m}$, still much longer than $x_{r}$. In Fig. 2 the external SQE curve for a lossless window layer is calculated with $\mathrm{L}_{\mathrm{e}}=29 \mu \mathrm{m}$, which gives a curve that is slightly higher than the data.

Setting the spectral reflectivity to zero gives the internal-SQE model curves shown in Fig. 2. From 1 to $2.1 \mu \mathrm{m}$ the internal $Q E$ is above $80 \%$, and it is over $90 \%$ between 1.4 and $2.1 \mu \mathrm{m}$. Absorption in the GaSb window layer causes the gradual decrease in the SQE beginning at $1.7 \mu \mathrm{m}$. Assuming complete photo-electron collection from a lossless window layer, the internal SQE is constant at $95 \%$ for wavelengths shorter than about $2 \mu \mathrm{m}$, as indicated in Fig. 2.

Remarkably long electron diffusion lengths have also been inferred from the SQE data of diodes with different emitter widths. The following relation describes the majority of our observations: $L_{e} \geq x_{e}$. Figure 3 shows our 


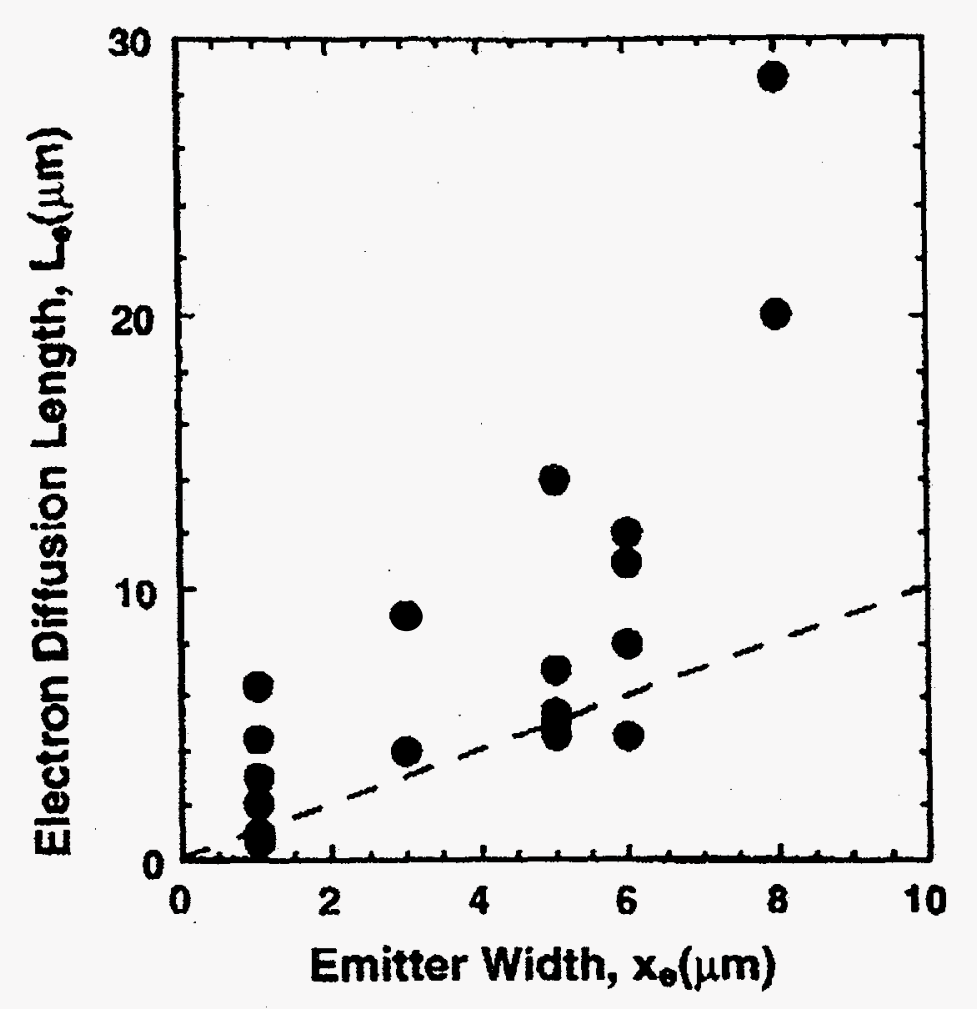

Figure 3. The inferred electron diffusion length for TPV diodes with emitter widths of 1 to $8 \mu \mathrm{m}$.

inferred values of $\mathrm{L}_{\mathrm{e}}$ for diodes with emitter widths of 1 to $8 \mu \mathrm{m}$. The dashed line in Fig. 3 denotes $L_{e}=x_{e}$. Twenty-one of the twenty-four data shown in Fig. 3 , or $88 \%$, lie on or above the line, strongly suggesting that the relation $\mathrm{L}_{\mathrm{e}} \geq \mathrm{x}_{\mathrm{e}}$ is valid.

The model also fits the SQE data reasonably well by assuming non-zero values of $S_{r}$ but consequently, even larger values of $L_{e}$ must be used. Our approach has been to assume that the smallest value of $\mathrm{L}_{\mathrm{e}}$ consistent with the data, is the most prudent estimation.

Measurements of the $Q E$ at $632.8 \mathrm{~nm}$ of diodes with different emitter widths corroborates the above results. Figure 4 shows the inferred internal $\mathrm{QE}$ 


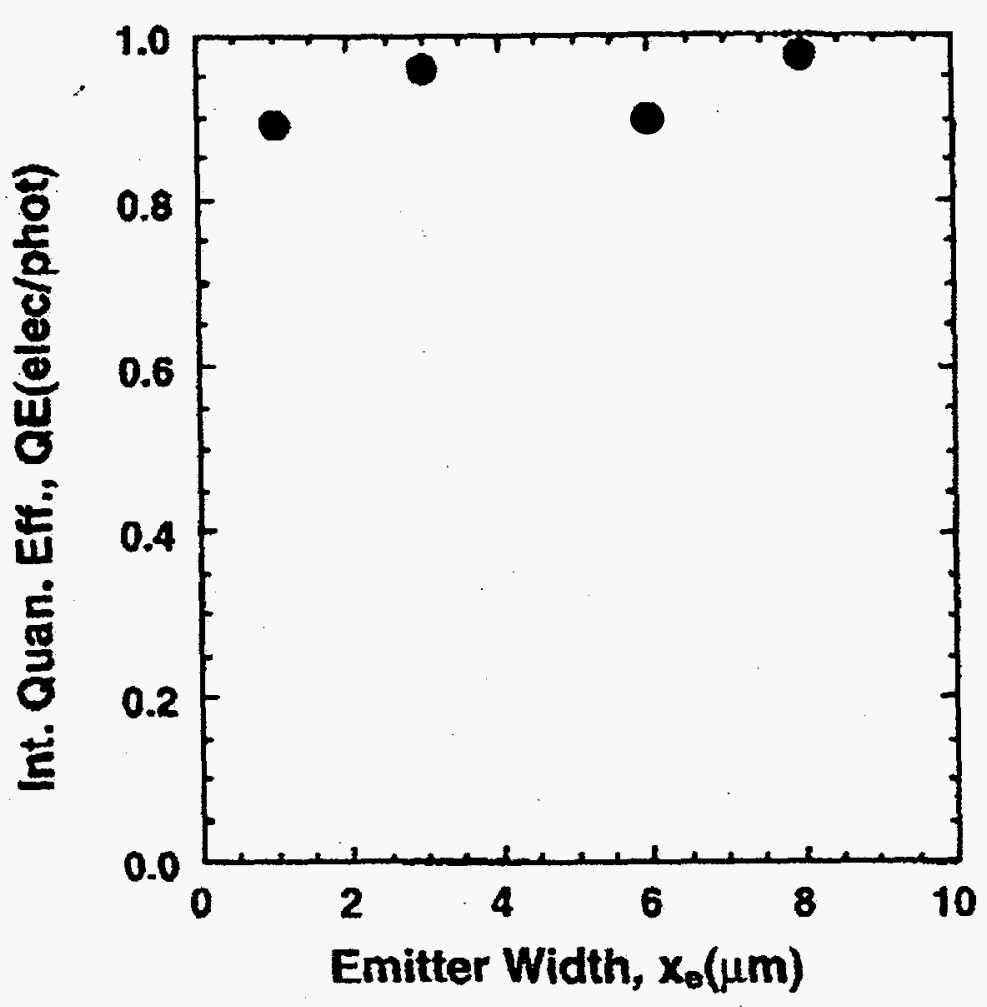

Figure 4. High internal quantum efficiency of TPV diodes at $632.8 \mathrm{~nm}$.

at $632.8 \mathrm{~nm}$ for diodes with $1-, 3-, 6-$, and $8-\mu \mathrm{m}$ emitters. Light at 632.8 has an estimated absorption constant in $0.56-\mathrm{eV}$ InGaAsSb greater than $10^{5} \mathrm{~cm}^{-1}$, so that photo-electrons are generated very close to the GaSb/InGaAsSb interface. It is also energetic enough to create more than one electron-hole pair in the InGaAsSb [8], which would increase the measured $\mathrm{QE}$. The measured internal $\mathrm{QE}$ is essentially independent of emitter width. Its high values between 89 and $98 \%$ strongly imply that $L_{e}>>x_{c}$ in basic agreement with the conclusions reached from our elementary analysis of the SQE data. They also suggest that the GaSb window is lossless.

To a lesser extent, we have observed the same phenomenon with respect to hole transport. Not as many wide-base diodes were measured, since efficient p-on-n TPV diodes will have wider emitters than bases, owing to the fact that electrons have the longer diffusion length. Figure 5 shows the dependence of 


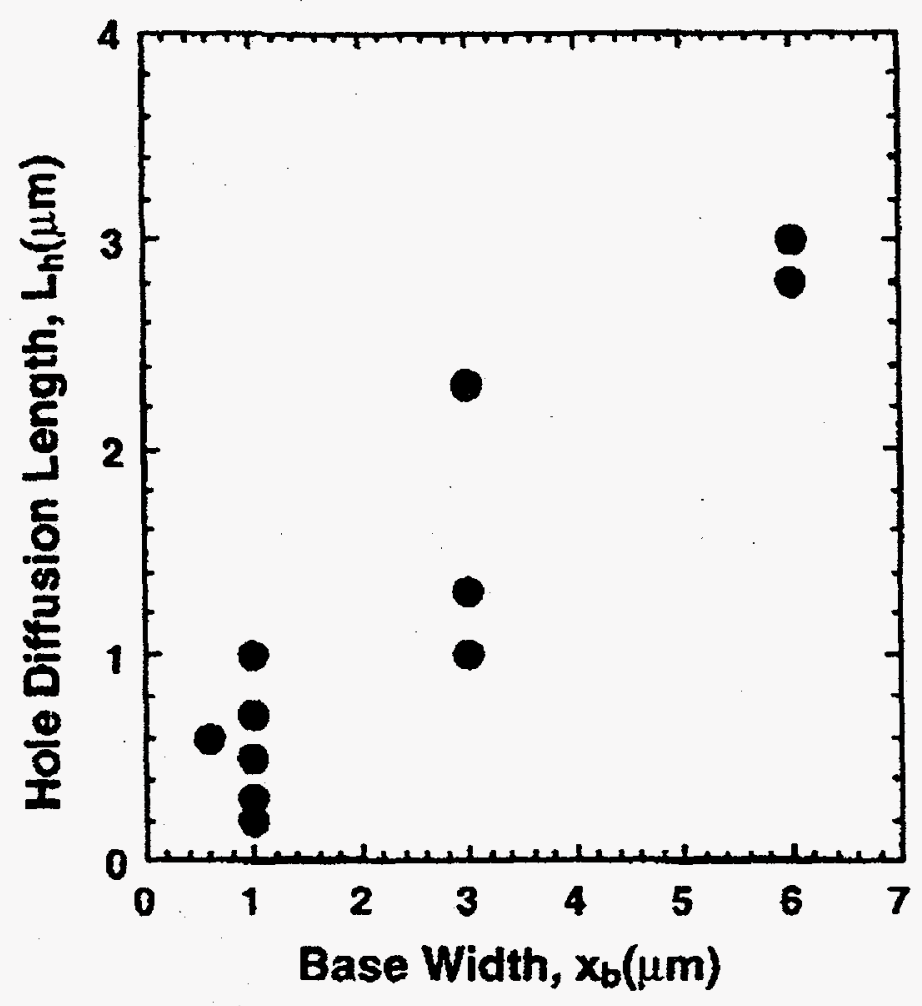

Figure 5. The inferred hole diffusion length for TPV diodes with base widths of 1 to $6 \mu \mathrm{m}$.

$L_{h}$ on base thickness. As in the case of electrons, the values of $L_{h}$ inferred from the model increase with increasing base width, but the magnitudes of $L_{h}$ for a given $x_{b}$ are only about one tenth that of electrons. This result may reflect the lower mobility and non-radiative lifetime of holes. The base layers of these diodes were doped an order of magnitude higher than were the emitter layers, which might decrease the holes' non-radiative lifetime.

\section{Conclusions}

In conclusion, we have shown that the transport of photo-generated electrons in $p-I n G a A s S b$ is very efficient. $p-o n-n$ IPV diodes with bandgaps of $0.56 \mathrm{eV}$ have external quantum efficiencies of $59 \%$ at $2 \mu \mathrm{m}$ and exhibit electron diffusion lengths of $29 \mu \mathrm{m}$ in an 8- $\mu \mathrm{m}$-wide emitter. The electron diffusion length appears to increase with increasing emitter width. Similarly, the hole diffusion length appears to increase with increasing base width, although the hole diffusion lengths are about one tenth those of the electron. These results were corroborated by the internal quantum efficiencies greater than $89 \%$ that were measured at $632.8 \mathrm{~nm}$. Given these results, an optimized InGaAsSb/GaSb p-on-n TPV diode with a 6- to 8- $\mu \mathrm{m}$-wide emitter will have an excellent spectral quantum efficiency. 


\section{References}

1. $1^{\text {to }}$ NREL Conference on the Thermophotovoltaic Generation of Electricity, Copper Mtn, CO, AIP Conf. Proc. 321 (1994)

2. $2^{\text {nd }}$ NREL Conference on the Thermophotovoltaic Generation of Electricity, Colorado Springs, CO, AJP Conf. Proc. 358 (1995)

3. G. W. Charache, J. L. Egley, L. R. Danielson, D. M. Depoy, P. F. Baldasaro, B. C. Campbell, S. Hui, L. M. Frass, and S. J. Wojtczuk, "Current Status of Low-Temperature Radiator Thermophotovoltaic Devices", presented at the $25^{\text {th }}$ Photovoltaic Specialists Conference, 1996.

4. H. Lee, D. Z. Garbuzov, R. U. Martinelli, R. J. Menna, and J. C. Connolly, "Molecular Beam Epitaxy of AlGaAsSb/InGaAsSb/GaSb Mid-Infrared High-Power Separate-Confinement Quantum-Well Lasers", to be presented at the Electronic Materials Research Conference, Ft. Collins, CO, June 25-27, 1997

5. H. Lee, P. K. York, R. J. Menna, R. U. Martinelli, D. Garbuzov, and S. Y. Narayan, "2.78 $\mu \mathrm{m}$ InGaAsSb/AlGaAsSb Multiple Quantum Well Lasers with Metastable Wells Grown by Molecular Beam Epitaxy", I. Crystal Growth, 150, 1354 (1995)

6. S. M. Sze, "Physics of Semiconductor Devices", $2^{\text {nd }}$ Ed., John Wiley and Sons, New York, 1981, pp. $802-805$.

7. J. Borrego, M. Zierak, and G. W. Charache, "Parameter extraction for TPV Cell Development", $1^{*}$ NREL Conference on the Thermophotovoltaic Generation of Electricity, Copper Mtn, CO, AIP Conf. Proc. 321, pp. 371-378 (1994)

8. T. Kobayashi, "Average energy to form hole-electron pairs in GaP diodes with alpha particles", Appl. Phys. Lett., 21, 150 (1972) 